\title{
Anillin expression is a marker of favourable prognosis in patients with renal cell carcinoma
}

\author{
HANNA RONKAINEN ${ }^{1}$, PASI HIRVIKOSKI ${ }^{2}$, SAILA KAUPPILA $^{2}$ and MARKKU H. VAARALA ${ }^{1}$
}

Departments of ${ }^{1}$ Surgery and ${ }^{2}$ Pathology, Oulu University Hospital and University of Oulu, 90029 OYS, Oulu, Finland

Received August 19, 2010; Accepted October 4, 2010

DOI: $10.3892 /$ or_00001051

\begin{abstract}
The clinical course of renal cell carcinoma (RCC) can be difficult to predict. In this study we evaluated the prognostic value of anillin and $\mathrm{Ki}-67$ in predicting survival in RCC. Immunohistochemical analysis using anillin and Ki-67 antibodies was performed on tissue microarrays constructed from paraffin-embedded specimens from 152 patients with primary RCC. The mean follow-up time was 90 months. Levels of anillin and Ki-67 staining were correlated with clinical factors, pathological features and survival. Anillin expression in cytoplasmic and nuclear fractions of the RCC cell line 786-O was examined using Western blot analysis. Cytoplasmic anillin immunopositivity was detected in 121 $(83 \%)$ tumours. Nuclear anillin expression was present in $40(27 \%)$ tumours and increased Ki-67 activity in $98(66 \%)$ tumours. A positive association was found between nuclear anillin and Ki-67 proliferation activity $(\mathrm{p}=0.005)$. The mean RCC-specific survival times for anillin immunopositive and immunonegative tumours were 158 (95\% CI 143-173) and 109 (78-141) months, respectively, with $\mathrm{p}=0.03$. Increased Ki-67 activity showed a tendency towards a poorer prognosis, although this was not statistically significant. In the Cox regression analysis for cytoplasmic anillin, nuclear anillin or $\mathrm{Ki}-67$ rate, and age, gender, stage and nuclear grade, the only significant factor in RCC-specific survival was stage $(\mathrm{p}<0.001)$. Western blot analysis showed anillin expression in both nuclear and cytosolic fractions of the RCC cell line. To conclude, anillin expression can be observed both in the cytoplasm and nuclei in patients with RCC. Cytoplasmic anillin expression is a marker of favourable prognosis in RCC patients.
\end{abstract}

\section{Introduction}

Renal cell carcinoma (RCC) is a cancer of increasing incidence and one of the most lethal urological malignancies with up to

Correspondence to: Dr Markku H. Vaarala, Division of Urology, Department of Surgery, Oulu University Hospital, PO Box 21, 90029 OYS, Oulu, Finland

E-mail: markku.vaarala@oulu.fi

Key words: prognostic marker, immunohistochemistry, survival, protein expression
$40 \%$ of patients eventually dying from cancer progression $(1,2)$. By the time they are diagnosed, up to one-third of patients already have a metastasised disease and half of the remaining patients will suffer a recurrence after curative treatment (3). Stage, the Fuhrman grade, histological subtype and many histological features like microscopic venous invasion, necrosis and sarcomatoid features are well-known prognostic factors for RCC $(4,5)$. However, there is currently no clinically useful immunohistochemical marker for evaluating the prognosis of patients with RCC. In the era of new targeted therapies there is a need for new prognostic factors for RCC so that the treatment and follow-up of individual patients can be planned more precisely.

Anillin (ANLN) is a protein with a calculated molecular weight of $124 \mathrm{kDa}$. Anillin cycles from the nucleus to the cell cortex (6) and regulates the contractile ring (7). It was originally identified as an actin-binding protein (8) but it also binds non-muscle myosin II (7) and at least some septins $(9,10)$. Anillin expression has been detected in several carcinomas (11).

Cell proliferation is a central process in malignancy. Cell kinetics can be studied using monoclonal antibodies against proliferation-associated antigens. These antigens are cycleassociated proteins and one of them is Ki-67 (12). The Ki-67 antigen is a well-characterized proliferation marker and its expression is linked with growth fraction of tumour cells (13). Of note, a significant linear relationship was detected between anillin and Ki-67 mRNA expressions in colorectal, lung, breast and lymphoid tissues (11).

The aim of this study was to examine the expression of anillin and Ki-67 proliferation activity in RCCs by immunohistochemistry and to clarify any associations between their expression and clinical characteristics of the tumours, and their prognostic significance. For this, we investigated a large set of RCCs consisting of different histological types and correlated the results with the clinical behaviour of RCC.

\section{Materials and methods}

Patients. The retrospective study group consisted of 152 patients treated with radical nephrectomy or renal resection for primary RCC at Oulu University Hospital, Oulu, Finland between 1990 and 1999. The median age of the patients was 63 (range 29-86) years, and $77(51 \%)$ patients were women and 75 were (49\%) men. Of the tumours, 7 (5\%) were resected and $145(95 \%)$ were operated on by radical nephrectomy. 


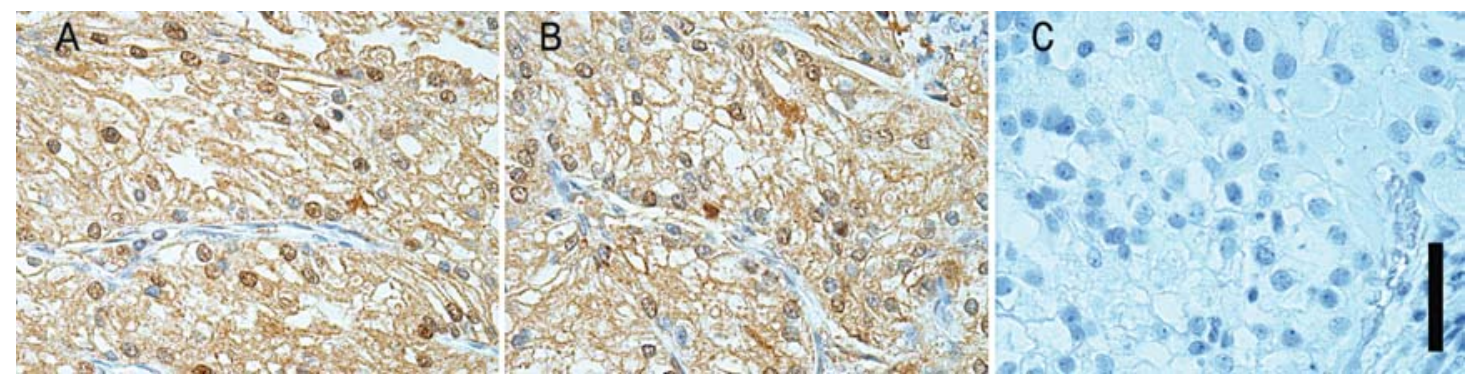

Figure 1. Anillin immunostaining in RCC. Immunohistochemical staining of anillin in RCC samples shows anillin expression in the cytoplasm and nuclei (A, B). Omission of the primary antibody (PBS) served as a negative staining control (C). Magnification x 400 , scale bar 50 $\mu \mathrm{m}(\mathrm{C})$.

The median follow-up time was 90 (range 0-209) months and follow-up was completed in all cases. During follow-up, 44 (29\%) patients died of RCC, 40 (26\%) died of other causes and $68(45 \%)$ patients were still alive. This cohort was described in a previous study (14-16). The research plan was approved by the local ethics board. The exact stage of the disease was recorded according to the TNM classification of RCCs (17). Archival material of formalin-fixed and paraffinembedded tumours was reclassified and graded according to the current WHO classification (18). The most representative area from each tumour block was selected for a multitissue array block.

Immunohistochemistry procedure. The antibodies used in immunostaining were a rabbit polyclonal antibody (IHC00298, Bethyl Laboratories, TX, USA, dilution 1:50) against anillin and a mouse monoclonal antibody (NCL-Ki-67-MM1, Leica Biosystems Newcastle Ltd., Newcastle Upon Tyne, UK, dilution 1:50) against Ki-67. First, 3- $\mu \mathrm{m}$ thick sections were deparaffinized in xylene, rehydrated in a descending ethanol series and washed in phosphate-buffered saline (PBS). The sections were then boiled in $0.01 \mathrm{M}$ citrate buffer ( $\mathrm{pH} \mathrm{6.0)}$ ) for $10 \mathrm{~min}$ or Tris-EDTA ( $\mathrm{pH} 9.0$ ) for $15 \mathrm{~min}$ in a microwave oven for anillin and Ki-67 staining, respectively. The sections were cooled for $15 \mathrm{~min}$ and washed twice in PBS. Endogenous peroxidise activity was eliminated by incubation in $5 \%$ hydrogen peroxide and absolute methanol. The bound anti-bodies were visualized using the EnVision system (DakoCytomation, Glostrup, Denmark). 3,3'-Diaminobenzidine hydrochloride (DAB) was used as the chromogen.

Cell culture. Renal cell adenocarcinoma cell line 786-O (CRL-1932) cells were purchased from the American Type Culture Collection (ATCC, Manassas, VA, USA). The cell cultures were maintained in RPMI-1640 (Sigma-Aldrich, St. Louis, MO, USA) supplemented with $10 \mathrm{mM}$ HEPES, $1 \mathrm{mM}$ sodium pyruvate, $2.5 \mathrm{~g} / \mathrm{l} \mathrm{D}$-glucose and $1 \%$ penicillinstreptomycin (Invitrogen-Gibco, Carlsbad, CA, USA), and they were added to $10 \%$ foetal bovine serum (HyClone, Logan, UT, USA) at $37^{\circ} \mathrm{C}$ in a humidified atmosphere of $5 \% \mathrm{CO}_{2}$.

Immunoblotting. Nuclear and cytosolic fractions of proteins from kidney cancer cell line 786-O were isolated using a Nuclear/Cytosol Fractionation Kit (Biovision, Mountain View,
CA, USA) as recommended by the manufacturer. After boiling the samples in reducing SDS sample buffer for $5 \mathrm{~min}, 10 \mu \mathrm{g}$ of protein was loaded per lane and the samples were electrophoresed on $10 \%$ polyacrylamide SDS gel and transferred to a PVDF membrane for anillin (IHC-00298, Bethyl Laboratories) or lamin A/C (NCL-LAM-A/C, Leica Biosystems Newcastle Ltd.) detection. For anillin detection, nondenaturating conditions were used as the samples were not boiled and $B$-mercaptoethanol was not used. Nuclear contamination of the cytosolic fraction was excluded by lamin $\mathrm{A} / \mathrm{C}$ staining (19-21). The binding of target proteins on the membranes was revealed by goat anti-mouse or goat antirabbit HRP-conjugated secondary antibodies (Santa Cruz Biotechnology, Santa Cruz, CA, USA). The protein bands were visualized by chemiluminescence.

Immunohistochemical evaluation of anillin and $\mathrm{Ki}-67$ expression. Cytoplasmic immunostaining for anillin was classified as negative or weak, moderately or strongly positive according to the intensity of the staining. For further analysis of cytoplasmic anillin, the subgroups with positive immunostaining were combined as positive. Nuclear immunostaining for anillin was classified dichotomously as negative or positive. Immunostaining for anillin was graded by three interpreters (H.R., P.H. and S.K.) without knowledge of the clinical data. The case-by-case final consensus grade was discussed and determined in a common session. Nuclear immunostaining for Ki-67 was evaluated as the percentage of stained nuclei and for further analyses tumours which showed immunopositivity over $10 \%$ were regarded as having an increased proliferative activity. One observer (H.R.) scored the Ki-67 staining.

Statistical analyses. Statistical analyses were performed using SPSS for Windows 15 (Chicago, IL, USA). Statistical significance between expressions and clinicopathological parameters was determined using the $\chi^{2}$ test or Fisher's exact test in the case of expected low frequencies. Corrected cancerspecific survival was analysed with the Kaplan-Meier curve and the significance with the log-rank test. The Cox regression model was used for multivariate analysis.

\section{Results}

Overall evaluation of immunostaining. Diffuse cytoplasmic anillin immunostaining was detected in 121 (83\%) cases 
1

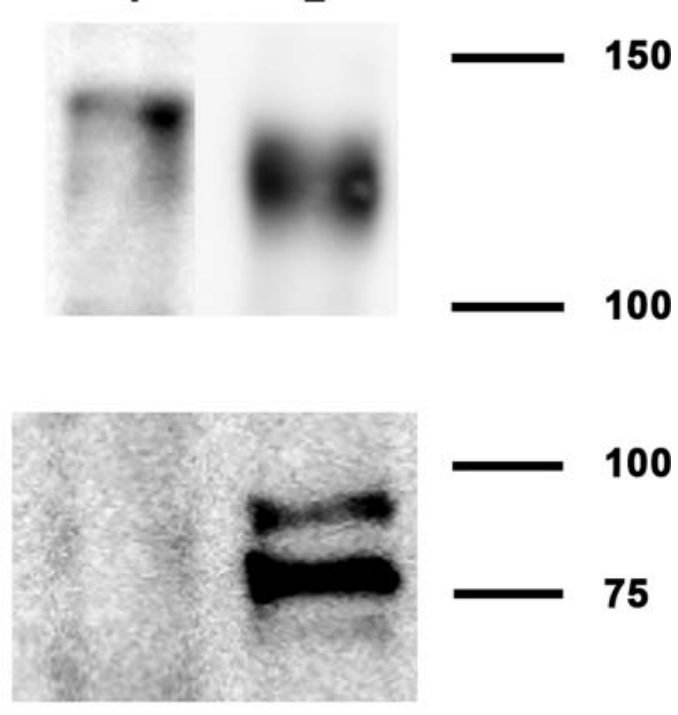

Figure 2. Anillin is expressed in cytoplasmic and nuclear fractions of the RCC cell line 786-O. Cytosolic (lane 1) and nuclear (lane 2) fractions were isolated and $20 \mu \mathrm{g}$ of protein was loaded onto the SDS-PAGE gel. Western blotting with anillin antibody staining (upper blot) mainly shows expression in the nuclear fraction, but some expression is present in the cytosolic fraction. The size of anillin protein was identical in both fractions, $\sim 120 \mathrm{kDa}$ (upper blot and data not shown). Lamin A/C expression (lower blot) is present only in the nuclear fraction, excluding contamination of the cytosolic fraction with nuclear content. Molecular weight markers (in kDa) are shown in the right margin. Representative blots from repeated experiments are shown.

(Fig. 1). Among these, the intensity of positive cytoplasmic staining was graded as weak in $70(48 \%)$, moderate in 43 $(30 \%)$ and strong in $8(5 \%)$ tumours. Nuclear anillin was present in $40(27 \%)$ tumours. Twenty cases $(13 \%)$ showed increased proliferative activity in Ki-67 staining.

Detection of anillin expression in the cytoplasm of the RCC cell line. Using nuclear and cytosolic fractions of the 786-O cell line, we detected anillin expression mainly in the nuclear fraction, but some expression was also present in the cytosolic fraction (Fig. 2), confirming the expression detected in RCC tissue samples.

Association of anillin expression and $\mathrm{Ki}-67$ activity with clinicopathological features of RCC. Cytoplasmic anillin expression was associated with the histological subtype of RCC. Clear cell and chromophobic carcinomas were more often immunopositive for cytoplasmic anillin than papillary and unclassified carcinomas (Table I). Cytoplasmic anillin expression was not associated with tumour class or nuclear grade. Tumours with an advanced stage were more often immunonegative for cytoplasmic anillin (Table I). Nuclear anillin expression was associated with a higher stage $(\mathrm{p}=0.02)$ but not with nuclear grade, tumour class or the histological subtype or RCC (data not shown).

The activity of Ki-67 was not associated with tumour class, stage, nuclear grade or the histological subtype of RCC (data not shown). Nuclear anillin and Ki-67 activity were associated with 96 (77\%) tumours with low Ki-67 labelling,
Table I. Association between cytoplasmic anillin expression and clinical and tumour characteristics in RCC.

\begin{tabular}{|c|c|c|c|}
\hline & \multicolumn{2}{|c|}{ Cytoplasmic anillin expression } & \multirow[b]{2}{*}{ P-value } \\
\hline & Negative $^{a}$ & Positive $^{a}$ & \\
\hline \multicolumn{4}{|l|}{ Tumour class } \\
\hline pT1 & $10 \quad(14)$ & $63(86)$ & \\
\hline pT2 & $5 \quad(45)$ & $6(55)$ & \\
\hline pT3 & $9(16)$ & 47 (84) & \\
\hline pT4 & $1 \quad(17)$ & $5(83)$ & 0.09 \\
\hline \multicolumn{4}{|l|}{ Clinical stage } \\
\hline $\mathrm{I}$ & $10 \quad(15)$ & $58(85)$ & \\
\hline II & $5 \quad(45)$ & $6(55)$ & \\
\hline III & $4 \quad(8)$ & $44(92)$ & \\
\hline IV & $6 \quad(32)$ & $13(68)$ & 0.009 \\
\hline \multicolumn{4}{|l|}{ Nuclear grade } \\
\hline I & $0 \quad(0)$ & $5(100)$ & \\
\hline II & 11 (14) & $69(86)$ & \\
\hline III & $7 \quad(18)$ & $31(82)$ & \\
\hline IV & $5 \quad(24)$ & $16(76)$ & 0.5 \\
\hline \multicolumn{4}{|l|}{ Histology } \\
\hline Clear cell & 18 (14) & $111(86)$ & \\
\hline Papillary & $4 \quad(40)$ & $6(60)$ & \\
\hline Chromophobic & $1 \quad(20)$ & $4(80)$ & \\
\hline Unclassified & $2(100)$ & $0 \quad(0)$ & 0.006 \\
\hline
\end{tabular}

aNo. of cases $(\%)$.

which were also immunonegative for anillin, and $11(55 \%)$ of the cases with increased Ki-67 activity were anillin immunopositive $(\mathrm{p}=0.005)$. No association was detected between cytoplasmic anillin expression and Ki-67 activity (data not shown).

Prognostic role of anillin in RCC. The RCC-specific survival was longer for anillin immunopositive tumours (Fig. 3). The mean RCC-specific survival times for anillin immunopositive and immunonegative tumours were 158 (95\% CI 143-173) and 109 (78-141) months, respectively, with $\mathrm{p}=0.03$. Nuclear anillin expression seemed to be associated with a tendency for a better prognosis in RCC-specific survival but this was not statistically significant (data not shown).

The Ki-67 activity showed a tendency towards a poorer prognosis, although this was not statistically significant $(\mathrm{p}=0.08)$. The mean RCC-specific survival times for high and low Ki-67 activity in RCC were 117 (95\% CI 76-158) and 155 (140-170) months, respectively.

In the Cox regression analysis for cytoplasmic anillin, nuclear anillin or Ki-67 expression, and age, gender, stage and nuclear grade, the only statistically significant factor in RCC specific survival was stage $(\mathrm{p}<0.001)$. 


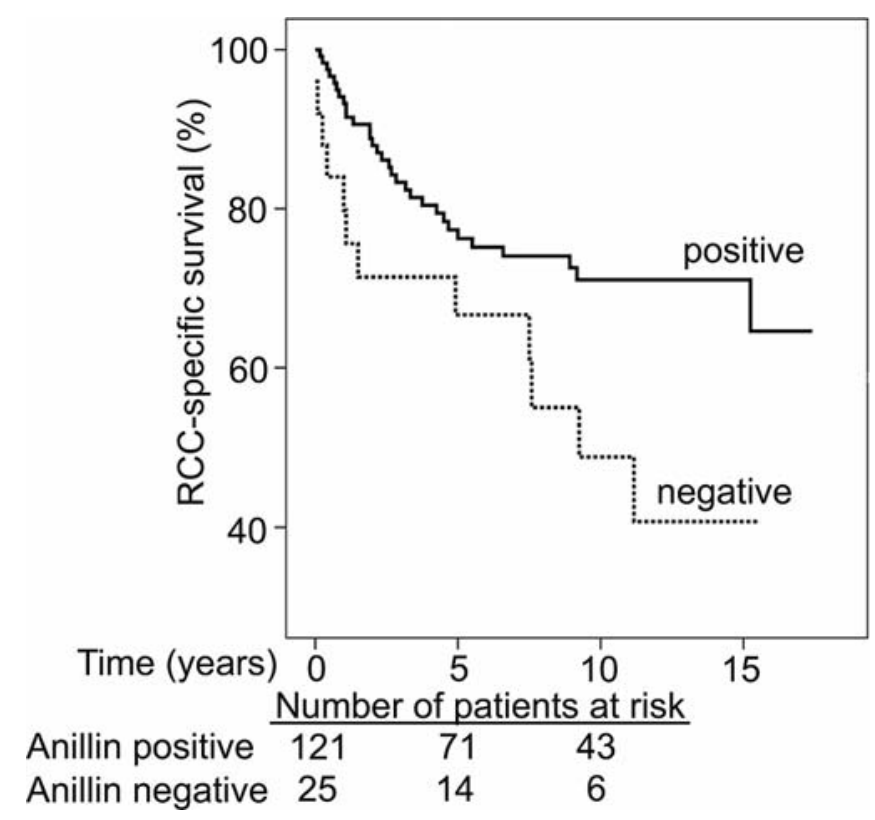

Figure 3. Association between anillin cytoplasmic immunopositivity in RCCs and RCC-specific survival. The number of patients at risk with 0,5 and 10 year follow-up is shown. The RCC-specific survival was significantly better among patients with cytoplasmic anillin immunopositive $\operatorname{RCC}(\mathrm{p}=0.03)$.

\section{Discussion}

In the present study, we characterised the expression of anillin in RCC and we found a significantly longer mean survival time, of approximately four years, among patients with tumours expressing anillin in the cytoplasm. We further proved the cytoplasmic expression of anillin in a human renal cell carcinoma cell line using cytosolic and nuclear fractions in Western blot analysis. Cytoplasmic immunostaining of anillin has been observed previously (11), but it was obviously considered to comprise unspecific binding in immunohistochemistry. However, cytoplasmic expression of anillin has been reported during interphase (9), which supports our findings.

The highest anillin expression was detected in the central nervous system (CNS). The median level of anillin mRNA was found to be higher in tumours than in normal tissues, with the exception of the CNS where anillin mRNA levels were higher in normal tissues than in tumours (11). Anillin mRNA expression has been studied during tumour progression in breast, ovarian, kidney, colorectal, hepatic, lung, endometrial and pancreatic tumours $(11,22)$. In all of these tissues there was progressive increase in anillin mRNA expression from normal to benign to malignant to metastatatic disease (11). Immunohistochemical staining of nuclear anillin in nonsmall cell lung carcinoma microarrays was associated with poor patient survival, indicating that this molecule might serve as a prognostic indicator (23).

The process of cell division involves a complex choreography of regulatory and structural events (24). Anillin is a key component which couples filament systems during cytokinesis, and it may influence their spatial organization $(6,9)$. The depletion of anillin may result in failure of cytokinesis (7). In normal tissues, nuclear anillin immunoreactivity does not often correlate with proliferative components, which may indicate that anillin might have non-proliferationassociated activities and roles in interphase nuclei (11).

In RCCs, Ki-67 was identified as an independent prognostic marker $(25,26)$. In conventional RCCs, the intensity of Ki-67 staining was positively correlated with primary tumour size and associated with disease stage and grade (27). However, due to the very low proliferative fraction identified by Ki-67, there are difficulties in its semi-quantitative assessment and the possibilities in routine pathological assessment are limited (26). In our study, there was no prognostic significance of the Ki-67 activity. This may be explained by the afore-mentioned technical and practical difficulties, and it may also be due to different populations and cohort sizes. However, we did observe a positive association between $\mathrm{Ki}-67$ and the nuclear expression of anillin, which supports the previous findings of positive association between Ki-67 and anillin mRNA levels in various different tissue samples (11).

The biological significance of cytoplasmic anillin expression remains unclear. Based on previous studies, the potential role during cytokinesis $(6,7,9)$ does not support the finding of better prognosis among patients with cytoplasmic anillin expression. In contrary, the presence of anillin in the cytoplasm of interphase cells (9) which may not be actively proliferating could explain the better prognosis of patients with cytoplasmic anillin expression.

In the present study we characterised the expression of anillin in the cytoplasm and nuclei of RCC specimens. Patients with cytoplasmic expression of anillin in their tumours had a better prognosis. Anillin immunostaining is a potential prognostic tool for clinical use and it should be evaluated in other RCC cohorts.

\section{Acknowledgements}

We would like to thank Ms. Mirja Vahera, Ms. Erja Tomperi and Ms. Mirja Mäkeläinen for their skillful technical assistance. H.R. has received grants from the Cancer Association of Northern Finland and from the Finnish Urological Association for this study.

\section{References}

1. Pantuck AJ, Zisman A and Belldegrun AS: The changing natural history of renal cell carcinoma. J Urol 166: 1611-1623, 2001.

2. Breda A, Konijeti R and Lam JS: Patterns of recurrence and surveillance strategies for renal cell carcinoma following surgical resection. Expert Rev Anticancer Ther 7: 847-862, 2007.

3. Bui MH, Zisman A, Pantuck AJ, Han KR, Wieder J and Belldegrun AS: Prognostic factors and molecular markers for renal cell carcinoma. Expert Rev Anticancer Ther 1: 565-575, 2001.

4. Cheville JC, Lohse CM, Zincke H, Weaver AL and Blute ML: Comparisons of outcome and prognostic features among histologic subtypes of renal cell carcinoma. Am J Surg Pathol 27: 612-624, 2003.

5. Lang H, Lindner V, Letourneux H, Martin M, Saussine C and Jacqmin D: Prognostic value of microscopic venous invasion in renal cell carcinoma: long-term follow-up. Eur Urol 46: 331-335, 2004.

6. Field CM and Alberts BM: Anillin, a contractile ring protein that cycles from the nucleus to the cell cortex. J Cell Biol 131: 165-178, 1995. 
7. Straight AF, Field CM and Mitchison TJ: Anillin binds nonmuscle myosin II and regulates the contractile ring. Mol Biol Cell 16: 193-201, 2005.

8. Miller KG, Field CM and Alberts BM: Actin-binding proteins from drosophila embryos: a complex network of interacting proteins detected by F-actin affinity chromatography. J Cell Biol 109: 2963-2975, 1989.

9. Oegema K, Savoian MS, Mitchison TJ and Field CM: Functional analysis of a human homologue of the drosophila actin binding protein anillin suggests a role in cytokinesis. J Cell Biol 150: 539-552, 2000

10. Kinoshita M, Field CM, Coughlin ML, Straight AF and Mitchison TJ: Self- and actin-templated assembly of mammalian septins. Dev Cell 3: 791-802, 2002.

11. Hall PA, Todd CB, Hyland PL, McDade SS, Grabsch H, Dattani M, Hillan KJ and Russell SE: The septin-binding protein anillin is overexpressed in diverse human tumors. Clin Cancer Res 11: 6780-6786, 2005.

12. Iatropoulos MJ and Williams GM: Proliferation markers. Exp Toxicol Pathol 48: 175-181, 1996.

13. Scott RJ, Hall PA, Haldane JS, van Noorden S, Price Y, Lane DP and Wright NA: A comparison of immunohistochemical markers of cell proliferation with experimentally determined growth fraction. J Pathol 165: 173-178, 1991.

14. Ronkainen H, Vaarala MH, Kauppila S, Soini Y, Paavonen TK, Rask J and Hirvikoski P: Increased BTB-kelch type substrate adaptor protein immunoreactivity associates with advanced stage and poor differentiation in renal cell carcinoma. Oncol Rep 21: 1519-1523, 2009.

15. Ronkainen H, Kauppila S, Hirvikoski P and Vaarala MH: Evaluation of myosin VI, E-cadherin and beta-catenin immunostaining in renal cell carcinoma. J Exp Clin Cancer Res 29: 2, 2010.

16. Ronkainen H, Soini Y, Vaarala MH, Kauppila S and Hirvikoski P: Evaluation of neuroendocrine markers in renal cell carcinoma. Diagn Pathol 5: 28, 2010.

17. Sobin LH and Wittekind C (eds): TNM Classification of Malignant Tumours (UICC). (6th edition). Wiley \& Sons, New York, 2002.
18. Ebele JN, Sauter G, Epstein JI and Sesterhenn IA (eds): Pathology and Genetics: Tumours of the Urinary System and Male Genital Organs (IARC). IARC Press, Lyon, 2004.

19. Gerace L, Blum A and Blobel G: Immunocytochemical localization of the major polypeptides of the nuclear pore complexlamina fraction. interphase and mitotic distribution. J Cell Biol 79: 546-566, 1978.

20. Gerace L and Blobel G: The nuclear envelope lamina is reversibly depolymerized during mitosis. Cell 19: 277-287, 1980.

21. Glass CA, Glass JR, Taniura H, Hasel KW, Blevitt JM and Gerace L: The alpha-helical rod domain of human lamins A and C contains a chromatin binding site. EMBO J 12: 4413-4424, 1993.

22. Olakowski M, Tyszkiewicz T, Jarzab M, Krol R, OczkoWojciechowska M, Kowalska M, Kowal M, Gala GM, Kajor M, Lange D, Chmielik E, Gubala E, Lampe P and Jarzab B: NBL1 and anillin (ANLN) genes over-expression in pancreatic carcinoma. Folia Histochem Cytobiol 47: 249-255, 2009.

23. Suzuki C, Daigo Y, Ishikawa N, Kato T, Hayama S, Ito T, Tsuchiya E and Nakamura Y: ANLN plays a critical role in human lung carcinogenesis through the activation of RHOA and by involvement in the phosphoinositide 3-kinase/AKT pathway. Cancer Res 65: 11314-11325, 2005.

24. Glotzer M: The molecular requirements for cytokinesis. Science 307: 1735-1739, 2005.

25. Bui MH, Visapaa H, Seligson D, Kim H, Han KR, Huang Y, Horvath S, Stanbridge EJ, Palotie A, Figlin RA and Belldegrun AS: Prognostic value of carbonic anhydrase IX and KI67 as predictors of survival for renal clear cell carcinoma. J Urol 171: 2461-2466, 2004.

26. Dudderidge TJ, Stoeber K, Loddo M, Atkinson G, Fanshawe T, Griffiths DF and Williams GH: Mcm2, geminin, and KI67 define proliferative state and are prognostic markers in renal cell carcinoma. Clin Cancer Res 11: 2510-2517, 2005.

27. Pertia A, Nikoleishvili D, Trsintsadze O, Gogokhia N, Managadze L and Chkhotua A: Immunoreactivity of p27(Kip1), cyclin D3, and Ki67 in conventional renal cell carcinoma. Int Urol Nephrol 41: 243-249, 2009. 